\title{
Transnational Corporations and Human Rights Duties: Perfect and Imperfect
}

\author{
Jilles L. J. Hazenberg ${ }^{1}$
}

Published online: 7 July 2016

(C) The Author(s) 2016. This article is published with open access at Springerlink.com

\begin{abstract}
This paper aims, firstly, to bridge debates on human rights and Transnational Corporations (TNCs) within practical philosophy and those within the business and human rights literature and, secondly, to determine the extent to which human rights duties can be assigned to TNCs. To justifiably assign human rights duties to TNCs, it is argued that these duties need to be grounded in moral theory. Through assessment of two approaches from practical philosophy, it is argued that positive duties cannot be assigned to TNCs because their bindingness cannot be grounded in moral theory. A positive argument is introduced to interpret TNCs' human rights duties as corresponding to virtues rather than rights. Though such duties are indeterminate regarding what constitutes adequate performance, they can be made more determinate through legal instruments outside of positive human rights law. An approach is introduced exemplifying how such approaches can achieve the end of TNCs compliance with human rights norms.
\end{abstract}

Keywords Transnational Corporations · Human rights · Philosophy · Perfect duties · Imperfect duties

\section{Introduction}

Transnational Corporations (TNCs) are increasingly powerful in our globalized world. Within a transnational context, TNCs challenge the power and duties that historically belong to states, and their often unregulated conduct affects public interests. Arguably, the most pressing cases are those in which TNCs infringe upon the ability of individuals to enjoy the content of their human rights. The conduct of a TNC may affect either

Jilles L. J. Hazenberg

j.1.j.hazenberg@rug.nl

1 Groningen Centre for Law and Governance, Faculty of Law, University of Groningen, Oude Kijk in 't Jatstraat 26, 9712 EKGroningen, The Netherlands 
the human rights of individuals involved within the business networks of that TNC (for example, the workers employed by a supplier of the TNC), or the human rights of individuals not involved within those networks (for example, through environmentally degrading practices), or both. Consequently, a growing number of academics, international institutions, non-governmental organizations (NGOs) and courts have sought ways to hold TNCs accountable for violations of human rights. There have been calls for a binding treaty regulating human rights-relevant conducts of TNCs within international law (UNHRC 2014; Weschka 2006). Such calls for hard law in this field seem to originate from the acknowledgment of the weaknesses of current soft law instruments and regulatory strategies such as the United Nations Guiding Principles (UNGPs) (UNHRC 2011). These proposals imply that TNCs have (limited) human rights duties and ought to be held accountable for violations of these duties. However, both the pressing reality of the increasing power of TNCs and academic and international efforts to assign human rights responsibilities to TNCs raise questions. Firstly, one may ask whether duties to avoid harming, to protect and to provide for human rights enjoyment can be assigned to TNCs. Secondly, one may ask to what extent the ability to hold TNCs accountable for infringements of human rights is limited by the duties that can be legitimately assigned to TNCs. Taken together, inquiry into these questions may shed light in the appropriateness of international human rights law and human rights mechanisms in regulating TNCs. This paper addresses these questions from a multidisciplinary perspective.

The first two sections consider the first question. Within existing international human rights law, states are the primary duty-bearer and private actors are only indirectly subject to obligations through state legislation. This article attempts to bridge the gap between philosophical approaches to TNCs and human rights and academic debates concerning proposals made within both legal academia and human rights practice. In practical philosophy, an on-going debate concerns whether it is possible to assign moral human rights duties to TNCs. Section II will introduce the approach taken by this paper regarding the moral duties corresponding to human rights. This approach is based on the premise that human rights require a source of bindingness outside of positive human rights law. It will be argued that the coherence between rights and duties within moral theory is crucial in providing the necessary moral grounding for human rights as claimable by the right holder. Consequently, it will be maintained that human rights require corresponding bearers of perfect duties, i.e. duties that are justifiably assigned to a specific actor who can adequately perform the duty without discretion (Meckled-Garcia 2008). In Sect. III, the problem of TNCs infringing upon human rights is introduced in detail. Section IV applies the conception of human rights duties to TNCs. In doing so, the section will assess two theoretical approaches from the literature that reconstruct TNCs as bearers of perfect human rights duties. It will be argued that both of these approaches fail and consequently that TNCs do not bear perfect human rights duties beyond the minimal negative duty to avoid harming the enjoyment of human rights.

In response to the second question, the extent to which TNCs can be held accountable for infringing upon human rights given the duties that can justifiably be assigned to them, a novel approach from contract law will be assessed. Moreover, the soft-law status of the UNGPs is shown to be consistent with TNCs moral duties. Section V, firstly, assesses the UNGPs and, secondly, interprets the novel approach from contract 
law as a means of limiting TNCs' discretion in discharging their imperfect duties through accountability mechanisms outside of human rights law. It will be argued that such approaches might be better equipped to achieve the goal of TNC compliance with human rights standards. Moreover, such an extra-human rights approach can attain TNC compliance without the need for legal human rights instruments. This is particularly important in light of this paper's conclusion that there are no moral grounds for binding human rights duties for TNCs.

\section{Human Rights and Corresponding Duties}

This paper follows a conception of human rights as claim rights grounded in moral theory. The present section will justify this conception. First, it will address the relationship between moral and legal human rights. Second, it will argue in favour of taking duties corresponding to rights seriously in the moral, as well as legal, justification of rights. Third, it will show how this conception of human rights explains certain features of current international human rights law and how this understanding relates to other conceptions of human rights.

Human rights are widely acknowledged to be moral claims that human beings can make in virtue of their humanity. If human rights are moral claims, then the source of their binding nature should be grounded in moral theory. Responses to the question whether TNCs are the bearer of human rights duties can therefore not be limited to questions of positive law alone, though such laws are ultimately required to establish legal rights. In order to properly investigate the source of bindingness of legal human rights duties for TNCs, one also needs to assess whether the philosophical justification of human rights can ground these duties in moral theory (Deva 2013).

This paper focuses on one aspect of philosophical justifications of human rights: the unity between rights and duties in moral theory. This unity is often attributed to Kantian legal philosophy and prescribes that a right must identify the bearer of corresponding duties within moral theory (Kant 1785; O’Neill 1996, 122-153; Meckled-Garcia 2008; Pogge 2002, 135-137). The source of bindingness thus lies in the identification of the moral duties, and their relevant bearers, corresponding to rights. Two questions constitute such a philosophical justification. The first concerns which aspects of our shared humanity have sufficient weight to generate counterpart duties. The second question addresses who holds these counterpart duties (O’Neill 2015, 71-78). ${ }^{1}$

For present purposes, it will be assumed that sufficient moral justification can be found for those rights entrenched in international human rights law. The paper will not examine the content of this justification, as human rights can be grounded in a wide range of values. ${ }^{2}$ Moreover, questions regarding this justification have been debated elsewhere, ${ }^{3}$ in much more detail than can be attempted here.

The focus on duties corresponding to rights challenges both exclusively legal notions and exclusively moral conceptions of human rights as "manifesto rights"

\footnotetext{
${ }^{1}$ From a non-philosophical perspective, a focus on duties has been advocated because such a focus "assumes that human rights are non-negotiable" (Deva 2014, 2).

${ }^{2}$ Such as needs, interests, a good life and dignity.

${ }^{3}$ For a recent overview of the justification and argument in favour of a pluralistic justificatory strategy, see John Tasioulas (2015).
} 
(Feinberg 1973, 64). The challenge to exclusively legal notions derives from the argument that embedding human rights in positive law alone is insufficient without also grounding these rights and duties in moral theory, thereby offering a philosophical justification, i.e. in corresponding and justifiable moral duties and rights. The focus challenges purely moral conceptions of human rights since it argues that a human right must be perceived as a claim that individuals can make towards others. Conceptions of human rights as manifesto rights fail to constitute such claims because they fail to specify the bearer of corresponding duties. Consequently, it is put forward that human rights constitute more than a moral good, forming instead the moral basis of legal claim rights.

The unity of rights and duties is often overlooked in human rights debates (Raz 2010, 1; O’Neill 2001, 1-2; Meckled-Garcia 2008; Douzinas 2000). As Joseph Raz $(2010,37)$ notes, in these debates, it is often proposed that stipulating the value of a right for the right holder is sufficient in establishing such a right within positive law. This, however, is only one side of the coin. It is crucial for arguments to stipulate and justify, within moral theory, onto which agents the moral duties corresponding to human rights fall. A failure to do so would prevent the moral claim from grounding a legal right, because no agent can be justifiably assigned the legal duty. Thus, the empirical fact that the conduct of TNCs does in some cases infringe upon the human rights of individuals is of itself insufficient to ascribe human rights duties to TNCs through positive law. ${ }^{4}$ Assigning this duty to TNCs must also be justified with reference to a corresponding moral duty sufficient to ground a right.

The justification of TNCs human rights duties consequently hinges on what moral duties they bear. The crucial question is which duties moral theory specify. Onora O’Neill $(1996,152)$ makes two distinctions between universal and special duties, and between perfect and imperfect duties, thus establishing four types of duties: universal perfect duties, universal imperfect duties, special perfect duties and special imperfect duties. Before elaborating on these four types of duties, the distinctions between universal/special and perfect/imperfect duties will be clarified. First, universal duties are those duties that fall equally on everyone capable of moral agency. They are generally described as negative duties, with correlative liberty rights (O'Neill 1996, 147). Second, special duties require positive action in the delivery of specific goods and services and therefore fall on specific actors. The counterpart rights to special duties are often coined "welfare” rights, or rights to goods and services (O’Neill 1996, 147-148). Third, perfect duties specify the relevant duty-bearer with no agent-directed discretion as to what constitutes an adequate performance of the duty (Meckled-Garcia 2008, 245). They provide the source of bindingness for claim rights. Finally, imperfect duties are duties that leave room for discretion in their performance. They are usually depicted as duties of charity, corresponding to charity rights that belong to the realm of virtues (Sen 2004, 341). Imperfect duties cannot ground claim rights because the duty does not specify the action needed for its fulfilment, or the person to whom the duty is owed. It only specifies that it is a moral good when imperfect duties are performed adequately.

\footnotetext{
4 'Infringe' is used here to refer to an empirical fact. As such, an infringement of human rights is not the same as the violation of human rights as a violation requires the inadequate of non-performance of a perfect duty assigned to specific actor.
} 
Universal perfect duties are duties "held by all and owed to all". They correlate to liberty rights of which the counterpart duty requires an omission or non-interference (O’Neill 1996, 151-152). In the literature, these are often depicted as negative duties (Pogge 2002). For instance, the right to free speech requires others not to interfere with your ability to express yourself. For free speech to be a right, ${ }^{5}$ this duty not to interfere with others' expression must necessarily be universal. ${ }^{6}$ Universal imperfect duties correspond to virtues constituting a moral good. Adversely, violations of these duties constitute a moral bad. However, universal imperfect duties are insufficient to ground moral rights because of the indeterminate nature of the action that the duty specifies. Such universal imperfect duties are "held by all, owed to none" and have no counterpart rights because they cannot be claimed (O’Neill 1996, 152). One such example is the universal imperfect duty not to lie. While it is a virtue not to lie, no one has a right to be spoken to truthfully at all times. ${ }^{7}$

Special perfect duties require a specific performance by the duty-bearer and are therefore "held by some, owed to specified others". In relation to human rights, "the specified others" are all human beings, thereby reflecting the rights' universality. Special perfect duties are generally taken to correspond to welfare rights, or rights to "goods and services", as these rights require the positive action of a specified agent towards specified others (O’Neill 1996, 141-146; Pogge 2002). For instance, the right to adequate housing requires specified agents that bear the positive duties to protect your housing and/or provide you with adequate housing. Given the resources that fulfilment of these rights requires, these duties cannot fall on everyone equally. ${ }^{8}$ Special imperfect duties correspond to virtues that constitute a moral good. Vice versa, violations of these duties constitute a moral bad. However, these duties do not fall on everyone equally; they are "held by some and owed to none" (O'Neill 1996, 152). For example, parents are under the special imperfect duty to establish a loving environment for their children, but this duty is insufficient to ground counterpart legal rights to a loving environment (O’Neill 1996, 151-152).

The distinctions raise the question of the implications for human rights generally and for legal human rights in particular. In general, it means that the philosophical justification of human rights must specify the bearer of a perfect duty, with no discretion as to what constitutes adequate performance thereof. Without this specification, the bindingness necessary for legal human rights to be claimable cannot be grounded in moral theory. When such a perfect duty cannot be assigned, the corresponding legal duty cannot justifiably be assigned in positive international human rights law due to the special nature of human rights as universal moral claim rights. There remain, however, imperfect duties that leave greater discretion to the duty-bearer as to what constitutes an adequate performance. Nevertheless, despite the fact that it is morally good to act on an imperfect duty, and blame can legitimately be put upon those who fail to perform them, such imperfect duties do not constitute counterpart rights. Human rights literature generally specifies three duties corresponding to human rights: the duties to respect,

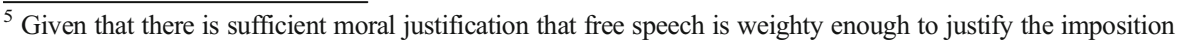
of binding duties upon others.

6 These negative duties are, within practice, mitigated through institutions.

${ }^{7}$ Whether these duties are perfect or imperfect relies at least partially on the justification of the value the proposed right protects. As stated above, I will remain silent on this justification.

${ }^{8}$ Moreover, performance of these duties is not compossible with all other special perfect duties.
} 
protect, and provide or fulfil. This paper will speak of the duty to provide rather than fulfil in order to avoid semantic confusion. ${ }^{9}$ Each will be interpreted in light of the unity of right and duty.

Firstly, the duty to respect is grounded in the duty to avoid harming. ${ }^{10}$ This duty to avoid harming must be a universal perfect duty "held by all, owed to all". As O'Neill $(1996,152)$ explains, this duty is negative in the sense that performance requires noninterference from the duty-bearer. This duty is thereby compossible with other duties, as the omission it requires does not interfere with any other universal perfect duty. The universality of this perfect duty in moral theory, however, does not imply that human rights are the most appropriate way to address violations of this duty. This is especially true in light of the lack of binding international human rights enforcement mechanisms. As Karp states, these universal perfect duties "pre-date the contemporary concept of human rights, and all other things being equal, can be covered outside of it - for example through criminal law - without the need for a new and distinctive set of international practices" (Karp 2014, 88).

Secondly, duties to protect and provide require positive performance by the dutybearer. Most often, this is through institutions that are capable of protecting the content of human rights for all and providing that content when these rights remain underfulfilled. Because these duties require active conduct from the duty-bearer and require the specific expertise and resources in order to be successfully performed, they cannot be universally assigned. Duties to protect and provide are special perfect duties that are held by some and owed to specified others. In relation to human rights, these specified others are all human beings in virtue of their humanity. The duty-bearers are those agents "with no general agent-directed discretion" towards the performance of the duty (Meckled-Garcia 2008, 245).

The requirement of corresponding perfect duties reinforces the moral and universal nature of human rights. The need for a philosophical justification of human rights in grounding legal human rights means that the corresponding duties must also be grounded in corresponding moral duties, regardless of being brought into legal practice through human rights law and vice versa. Moreover, the current human rights practice, as specified within the different declarations and charters, arguably reflects a perception of human rights as moral claims requiring corresponding perfect duties. However, international human rights law notoriously isolates the state as the sole addressee of human rights and thereby as primary duty-bearer.

When viewed in light of the unity of right and duty, the isolation of the state can be explained with reference to the specific public role of states. Consequently, the state is arguably the relevant actor, both according to moral and legal justifications, to bear the special perfect duties corresponding to human rights. There is, however, nothing in moral theory that necessarily excludes other actors from also bearing these duties. Within international human rights law, any secondary duties are mitigated through the state. In relation to the universal perfect duty to avoid harming the enjoyment of rights, legal human rights are crippled within the transnational context due to the centrality of

\footnotetext{
${ }^{9}$ For instance, a right can remain unfulfilled due to it being not provided for or because its content is unprotected.

${ }^{10}$ This is most clear in the institutional sense in the General Comment 12 of the UN Committee on Social, Economic and Cultural Rights, 1999.
} 
the state as the only specified duty-bearer. Within states, this duty is often mitigated through constitutional and criminal law and the content of human rights might, within this national context, better be covered outside of human rights law. ${ }^{11}$ Outside of the state, there are no such mechanisms beyond soft-law, such as the United Nations Guiding Principles (UNGP) which, grounded explicitly in the moral duty to do no harm, seek ways of engendering respect for this duty in light of absent enforcement mechanisms.

\section{The Problem: Transnational Corporations Infringing Upon Human Rights}

Recent years have shown an increase in debates concerning human rights duties of private actors. Questions concerning possible duties of TNCs have had a particularly prominent position. It has been argued that TNCs violate human rights, assuming that at least some perfect human rights duties can be assigned to them, and that they have duties to protect and provide for human rights, assuming that special perfect human rights duties can be assigned to them (Cernic 2010; Weschka, 2006). Cases that trigger these arguments are afloat, especially in contexts of weak and/or unwilling governance by the state. Moreover, the increasing power and resources of TNCs often exceed those of states. This not only makes TNCs powerful on the global level, but it also makes states increasingly reluctant to regulating TNCs' conduct. In response to this void calls for human rights, obligations and responsibilities for TNCs are becoming increasingly frequent. Nonetheless, it presently remains impossible, legally speaking, for TNCs to violate human rights under international human rights law.

Arguments can be found regarding TNCs' complicity in human rights violations perpetrated by states, whereby the TNC participates in state conduct that violates human rights. This is the case, for instance, when a tech-company turns over information concerning the identity of social media users to authoritarian governments (Dann and Haddow 2008, 219). Moreover, TNCs have been said to directly violate human rights in zones of weak governance where the state is unable or unwilling to perform its legal human rights duties. For example, it has been argued that Shell has participated in human rights violations in the Niger Delta. Operating in a context of weak governance as the de facto principal authoritative actor, it can be said that Shell was not merely complicit in state violations but actively violated human rights themselves. The cases against Shell, unsuccessfully brought before American courts under the Alien Tort Claim Act (ACTA), are an example of arguments presented that a TNC was involved in direct human rights violations (Enneking 2012, 396-400). ${ }^{12}$ Furthermore, TNCs producing goods in Southeast Asia under degrading work conditions have been said to harm and violate workers' human rights (MeckledGarcia 2013, 122; Teubner 2006, 328).

\footnotetext{
${ }^{11}$ Not in the least because of the demanding nature of the justification of human rights duties through moral duties. Within the national context, the imposition of legal (non-human rights) duties on actors can be justified through other mechanisms such as efficiency and democracy.

${ }^{12}$ For a brief overview and Esther Kiobel et al. v. Royal Dutch Petroleum et al., 621 F.3d 111 (2nd Cir. 2010), at 123. See also Wiwa v. Royal Dutch Petroleum Co., 226 F.3d 88 (2nd Cir. 2000), at 92-93 for an overview of the factual background of the cases.
} 
Given that TNCs are capable of moral agency, as has been forcefully argued elsewhere, ${ }^{13}$ they are potential human rights duty-bearers despite not currently bearing such duties within positive human rights law. Coupled with the examples in which it has been argued that TNCs violate human rights, the possibility of assigning human rights duties to TNCs begs assessment. Two possible approaches are explored from the literature. Firstly, it has been argued, predominantly in philosophical debates, that TNCs are relevant actors to assign special perfect duties to in contexts of weak and/ or unwilling state governance. Consequently, these arguments intend to provide the necessary philosophical justification for human rights duties. Secondly, a growing literature on business and human rights has proposed methods to achieve the accountability of TNCs by enforcing their assumed human rights duties through soft-law norms, extra-legal enforcement and proposals for a binding treaty. ${ }^{14}$ Given that the source of bindingness of human rights duties must be grounded within moral theory, legal enforcement mechanisms require that TNCs actually bear these duties. This section will assess two approaches from practical philosophy that seek to construct TNCs as bearer of special perfect duties to protect and provide for human rights. Establishing which duties can be assigned to TNCs is central to determining what mechanisms are appropriate to regulate them. In other words, the question of which duties TNCs bear is therefore logically prior to assessing proposed or existing legal mechanisms. The approaches evaluated here attempt to provide the source of bindingness and construct TNCs as relevant subjects of human rights regulations and possible positive law.

Two criteria are taken to be the key to judging the abovementioned approaches, one from moral theory and one from practice. The first criterion bases itself on the unity between duty and right in practical philosophy. It prescribes that for TNCs to be relevant subjects of legal human rights mechanisms, they must bear the counterpart perfect duties in moral theory as the source of their bindingness. Thus, any duty assigned to TNCs by either of the approaches must be a perfect duty with no discretion as to what constitutes adequate performance. The state-centric institutional framework of international law informs the second criterion. International human rights law has well-known and extensively elaborated-upon enforceability deficiencies, mostly attributed to its exclusionary focus on states as its sole subjects. A critical view of this statecentrism in international law requires a close scrutiny of the role of states in the regulation of TNCs aiming to bring TNCs into compliance with their human rights duties. As Deva points out, if states bear "the exclusive responsibility of enforcing human rights norms against companies, it will do little (...)" towards achieving TNCs' compliance (Deva 2014, 3). Any approach therefore benefits from minimal involvement of the state as primary duty-bearer and regulator and is assessed accordingly.

Failure to meet these criteria leads to unjust outcomes and potentially undermines the nature of human rights as moral claims and the threat of human rights inflation. ${ }^{15} \mathrm{~A}$ failure is unjust in cases when legal mechanisms are proposed that hold TNCs accountable for violations of duties that are not sufficiently grounded. If there are no

\footnotetext{
${ }^{13}$ For excellent expositions of such an argument, see David Jason Karp (2014, 7-11) and Philip Pettit (2007, 171-201).

${ }^{14}$ For an excellent overview, see Surya Deva and David Bilchtiz (2013).

15 As human rights then collapse into 'manifesto' rights.
} 
perfect duties assigned, a possible regulation assigning human rights obligations on TNCs has no justified source of bindingness in moral theory. Moreover, regarding the second criterion, if the state remains central to enforcement and accountability mechanisms, any proposed regulation by the state fails to address the fact that TNC infringements most often take place in the cases of weak and/or unwilling governance by the state.

\section{TNCs and Special Perfect Duties: the Capacity and Publicness Approach}

Towards determining whether TNCs bear special perfect duties, two approaches, recently brought forward within practical philosophy, are assessed. Both approaches seek to construct TNCs as bearers of special perfect duties, i.e. duties to protect and provide, in contexts of weak and/or unwilling governance: the capacity and publicness approach. ${ }^{16}$ This section assesses the two approaches on their internal consistency and in light of the criteria established in the previous sections.

A view hinted at by Onora O'Neill (2001, 2004) and Robert E. Goodin (1988), and advocated by Leif Wenar (2007), is best described as the "capacity approach" (Karp 2014, 89-151; Miller 2001). The approach acknowledges that within the institutional framework of international law, states are the primary agents and therefore necessary to discharge the duties corresponding to human rights. However, these authors argue that because many states do not perform the duties corresponding to their role as primary agent, it is arbitrary to exclude all other actors as potential bearer of human rights duties. ${ }^{17}$ The capacity approach promises to provide a consistent metric of assigning special perfect duties to the relevant private actors. The capacity approach states that human rights duties fall on those who have the capacity to protect and provide for human rights at not excessive costs (Wenar 2007; Meckled-Garcia 2009, 268). One of its critics has, as is often the case, described it most consistently:

"whichever agent or agency B has the capacity most effectively to protect or provide for X's human rights, at least cost to self relative to other agents, and can do so at a cost to self that is not excessive, has a primary responsibility to protect and provide for X's human rights" (Karp 2014, 106)

The view is best seen as bridging the gap that exists in cases where the state as primary agent is unable or unwilling to fulfil the duties assigned to it by human rights law. This is exemplified by the current reality of impunity of many conducts of private actors that infringe upon human rights. In those instances, secondary agents such as TNCs are assigned the special perfect duties to protect and provide, given that they have the necessary capacity and can do so without suffering excessive costs. As such,

\footnotetext{
16 These approaches favour conceptions of human rights such as the one adopted in this paper. Thereby, they both reject purely moral conceptions of human rights as manifesto rights or moral goals, and positivist legal conceptions of human rights as those rights entrenched within international human rights law.

${ }^{17}$ Philosophical conceptions of human rights often justify the state as primary duty bearer because of their role as sovereign public actor (i.e. through role responsibility). There is nothing, however, that necessarily excludes other agents as primary, or secondary, duty bearers, especially given the fact that in our non-ideal world, states often do not live up to their ideal theory constructions. See O’Neill (2004, 246-247 and 256-258).
} 
TNCs are called upon to assume that the duties states fail to discharge. An example will illustrate what the capacity approach entails. Imagine a corporation active in a remote section of the Amazonian rainforest where the state has little influence. This corporation, as part of its employment agreement, provides basic preventive health care to its employees, providing a basic human right. The capacity approach prescribes that in such cases, the corporation has the duty to protect and provide for this basic human right not only for its employees but also for others living in the region in which the corporation operates, given that it can do so without bearing excessive costs.

Taking the demanding nature of special perfect duties corresponding to human rights seriously, this approach has built in a cut-off point with regard to excessive costs. As the example shows, assigning duties through the metric of capacity can indeed lead to high costs, such as providing health care. However, the "excessive-cost clause" proves to have limited bearing in constructing TNCs as a relevant duty-bearer in moral theory. 18 The excessive costs-clause is unable to mitigate all issues relating to the actual costs of the approach. This leads to unequal outcomes and great discretion in discharging perfect positive duties (Miller 2001, 460-462; Meckled-Garcia 2009, 268-271; Karp 2014, 108-115). Imagine two corporations operating in a bad or no-governance zone. One of these infringes upon the basic human rights of the local community through arbitrary arrests by a private police force. ${ }^{19}$ According to the capacity approach, the actors capable to "most effectively" protect and provide for basic human rights have a duty to do so if it can do so without bearing excessive costs. However, it might be that the corporation not infringing upon the human rights of the local community has the capacity to most effectively protect these rights. The burden the approach puts on this corporation is excessive given that it did not contribute to the infringement by the other corporation. The approach cannot distinguish between the actor infringing upon rights and the relevant bearer of special perfect duties.

The question whether capacity can ground special perfect duties consistently with the criteria set out in the previous sections must be answered negatively. Though capacity might provide a metric of assigning special perfect duties within moral theory, it is problematic when applied to TNCs. ${ }^{20}$ The costs corresponding to performance of the special perfect duties to protect and provide human rights are high, which the approach intends to deal with through the excessive cost-clause. However, the fulfilment of the special perfect duties hinges entirely on the assessment of these costs. This undermines the no-discretion requirement needed in discharging special perfect duties. For instance, the TNC not infringing upon human rights, but with the capacity to protect and provide, can reasonably argue that the performance of this duty will amount to excessive costs. Just as the corporation providing basic preventive health care to

\footnotetext{
${ }^{18}$ One might argue that the excessive cost criterion in the capacity approach fails to assign special perfect duties at all. That this is not the case can be shown by reference to reality: No agent is capable of discharging all duties perfectly. We need 'imperfect' institutions to regulate these duties; however, these 'practical' duties must be grounded in moral perfect duties, otherwise there is no justification for their bindingness outside of positive law.

${ }^{19}$ This was arguably the case in Kiobel $v$ Royal Dutch Petroleum Co. and Wiwa vs. Royal Dutch Petroleum $C o$. in which Shell itself requested and compensated military assistance that took part in human rights violations.

${ }^{20}$ For a more elaborate argument against the capacity approach, see Meckled-Garcia $(2009,259-276)$ who argues that the capacity approach, rather than providing a metric of assigning human rights duties, collapses into a theory of global distributive justice.
} 
employees can argue that it does enough to discharge its responsibilities and that any further duty to protect or provide would amount to excessive costs. The assessment of excessive costs is not allocated outside of the TNCs' judgment but is left to the discretion of the TNCs themselves. Consequently, this leaves the performance of the duties to protect and provide to the discretionary assessment of what amounts to excessive costs. $^{21}$

David Jason Karp has recently rejected the capacity approach because it lacks "further explanation of which agents can legitimately bear the costs to self associated with human rights (...) and why" (Karp 2014, 115). He advocates the "publicness approach" (Karp 2014, 116-151). This approach takes the "publicness" of a private actor, and TNCs especially, as metric to assign special perfect duties. ${ }^{22}$ Publicness refers to the role a private actor plays in a certain context. If an actor is relevantly public, then duties to protect and provide can be assigned to them. Relevant publicness is constituted when an actor has both accepted and is "accepted as having authority to act on behalf of the collective as agents with a "primary political role" (Karp 2014, 143). There are cases in which TNCs provide basic public goods to individuals in contexts of weak or unwilling governance. However, as Karp acknowledges, simply delivering public goods or performing a primary political duty, such as policing, is not sufficient to render a private actor relevantly public. The public must accept the primary political role exercised by the TNC just as the actor itself needs to accept this role. Without this acceptance, it is possible for "relevantly public" to be arbitrarily assigned to any actor delivering a public good.

Assigning such a public role to TNCs under the condition that this role must be accepted by both the public and the TNCs is not as farfetched as one might intuitively think. Recent years have seen a significant increase in codes of conduct, sustainability measures and corporate social responsibility efforts by TNCs. The "social expectations" the larger public has of TNCs has increased and TNCs have taken on these expectations, at least partially, by introducing the mentioned measures and programmes (UNCHR 2011). However, as Karp states, the publicness approach "hinges primarily on the willingness of a particular actor, group, or institution to exercise political authority" (Karp 2014, 145). Within moral theory, it might well be that a conception of publicness constitutes the relevant agent bearing special perfect duties. $^{23}$ Within our non-ideal world, however, such a conception cannot ground perfect duties, due to the discretion stemming from the voluntariness of accepting a public role.

While the publicness approach overcomes the issue of excessive costs and the allocation thereof, it leaves the performance of the duties to protect and provide hinging on their acceptance by TNCs. Karp acknowledges that the publicness approach is

\footnotetext{
${ }^{21}$ One might argue that the same argument undermines assigning human rights duties to states when applied to them. That this is not the case hinges on the nature of states as sovereign public actor and source of law. States' primary task is to promote the public good, and in promoting the most basic instances of this good, i.e. human rights, only costs above all available resources constitute 'excessive' costs. In other words, even if costs are excessive for a state, this does not alleviate them from their human rights duties but rather constitutes a (moral) obligation of the international community to assist. Moreover, this also grounds the common argument that human rights are, if anything else, a cap on sovereignty and justification of interference. See for instance Rawls (1999) and Miller (2001).

22 This correlates to the 'role responsibility' through which states are often isolated within moral theory as relevant duty bearer.

23 See $n 17$.
} 
capable of gaining results only in the long term and leaves the rights of individuals under-fulfilled through non-performance of human rights duties. The rights of individuals remain under-fulfilled because of the likely withdrawal of "capable non-state agents from governance functions, in order to make space for the establishment of robustly 'public' institutions, which accept the responsibility to protect and provide for rights in the medium to long term" (Karp 2014, 151). Karp appears to focus on the wrong actor; if publicness is the relevant criterion and the aim is to achieve the fulfilment of rights in the medium to long term, it appears that the state, as a public actor, is more relevant than a TNC. The publicness approach reconstructs private actors as public actors in order to assign them special perfect duties that are appropriate for public actors to bear. However, given the limited publicness of private actors and the necessary condition that they accept themselves as being relevantly public, the approach fails both in constructing TNCs as relevantly public and in assigning to them special perfect duties. ${ }^{24}$

Both the capacity and publicness approaches fail to assign special perfect duties to TNCs. They thereby fail to ground binding human rights duties to protect and provide in moral theory, beyond the minimal negative duty to avoid harming. This conclusion has profound consequences for the regulation of TNCs. The growing literature on business and human rights has greatly increased during the process of consultations and the drafting of the United Nations Guiding Principles on Business and Human Rights (UNGPs). Significant debate concerns the status of soft-law norms, such as the UNGPs, and a potential need for a binding treaty (Weschka 2006). One consequence is that, in opposition to what some argue (Weschka 2006; Knox 2012; Nolan 2013), the inability of the above approaches to ground special perfect duties for TNCs in moral theory indicates that the codification of such duties in a binding treaty is unjustifiable. A failure to ground such duties outside of positive international human rights law does not reflect the nature of human rights as rights that we have by virtue of our humanity, rather than by virtue of the political community we are a part of or the state of which we are citizen. ${ }^{25}$ A different consequence is that soft-law norms such as the UNGPs require critical analysis to assess the ground of bindingness of the duties they assign, especially in order to determine what their relation is to duties corresponding to rights (perfect) and duties corresponding to good morals and virtues (imperfect) (Deva 2013). It will be argued that such soft-law norms are grounded imperfect duties. However, the "wiggle room" that imperfect duties and soft-law norms leave in discharging responsibility can be limited through the use of legal instruments other than human rights (Nolan 2013, 160).

\footnotetext{
${ }^{24}$ As with the capacity approach, one might question the status of this argument by applying the approach to states. Similar to the response in $\mathrm{n} 21$, the 'publicness' of states is not debated as they are the primary and sovereign public actors. Consequently, they bear these perfect duties because of this nature. What constitutes adequate performance is indeed left to states' discretion precisely because their nature as primary sovereign public actor. If, however, the performance of human rights duties is objectively and grossly inadequate, this violation of human rights is a justification for the international community to interfere (see n21).

${ }^{25}$ This means that states can, through instruments other than human rights law, impose legal duties upon TNCs. However, the general reluctance of states to do so, especially internationally, informed the second criterion of minimal state involvement. Therefore, these instruments are not assessed here, though it is accepted that in general, states have a (moral) obligation to do so.
} 


\section{TNCs, The Universal Perfect Duty and Imperfect Duties: Legal Instruments}

As stated in "Human Rights and Corresponding Duties" section, the universal perfect duty to avoid harming corresponds to liberty rights. The performance of this duty requires non-interference and refraining from actions harming the content of the counterpart liberty right. ${ }^{26}$ For such liberty rights to exist, the duty to avoid harming must be assigned to everyone. This is because if one individual or institution is above the law, i.e. without duty, the liberty right is indeterminate. The positive actions required for liberty rights are special perfect duties such as establishing a police force and a minimal rule of law. Precisely these types of duties cannot be assigned to TNCs. Soft-law norms such as the UNGPs leave great indeterminacy in the performance of the duties they assign. To a great extent, this is due to the lack of both national and international enforcement mechanisms. On the one hand, this explains the calls for binding law regulating TNCs' conduct, but on the other, it raises questions concerning the moral status of the duties such norms assign to TNCs and ultimately whether these can be justifiably enforced.

John Ruggie, the author of the UNGPs, grounds them in the duty to avoid harming (UNHCR 2011). ${ }^{27}$ The core of the UNGPs requires businesses to refrain from infringing upon human rights, i.e. to avoid harming. However, the UNGPs appear to overstretch the extent to which this universal perfect duty can ground legal duties. The inclusion of "due diligence" has led Ruggie to conclude that "doing no harm is not merely a passive responsibility for firms but may entail positive steps" (UNHCR 2011, 7). What these positive steps entail "will depend on circumstances" in which a business operates (UNHCR 2011). Viewed in light of the unity of rights and duties, these statements raise concerns as to the moral grounding of these duties. The duty to avoid harming requires avoiding actively harming the rights of others. In its widest interpretation, this requires that any action by any actor cannot leave others worse off than they were prior to the action (James 2012). This wide requirement does not, however, constitute positive actions that fall under the scope of due diligence set out by Ruggie. It is often the case that even actions that infringe upon the rights of individuals leave these individuals better off than they were if no action had been carried out. ${ }^{28}$ The UNGPs sit uneasily between their soft-law nature and the inability to ground all of the duties they assign in perfect moral duties.

However, it might be that the UNGPs are better conceived as being grounded in imperfect special duties. Interpreted that way, they represent an effort to limit the wiggle room that imperfect duties leave regarding their performance. Moreover, this interpretation explains the soft-law nature of the UNGPs as it is consistent with their grounding in imperfect special duties. Such an interpretation opposes the idea that the UNGPs are a first step towards establishing "a treaty that holds MNEs and other business enterprises directly responsible under international law for human rights

\footnotetext{
$\overline{26}$ This does not imply that liberty rights do not also have counterpart special perfect duties such as setting up a police force and establish institutions capable of implementing a rule of law.

27 '[T]o do no harm' is the phrase he uses.

${ }^{28}$ For instance, working under degrading conditions leaves these employees better off than they would be in conditions of unemployment.
} 
violations" because the duty has no counterpart claim rights (Weschka 2006, 656). Grounded in imperfect duties, the UNGPs do not incur in the "shortcomings regarding the legal status of UN-norms" (Weschka 2006, 656). When grounded in imperfect duties, the UNGPs do not reflect the shortcomings of UN-norms at all. They are an effort to achieve a morally better outcome given that TNCs cannot bear special perfect duties. The remainder of the paper will show that imperfect duties are not without weight. They can be legitimately enforced through mechanisms other than human rights law in order to minimize discretion in their performance. The wiggle room for TNCs in discharging their duties will thereby be limited.

Failing to assign duties to protect and provide human rights to TNCs does not undermine the moral status of the envisaged endpoint: the avoidance of infringements of TNCs upon the human rights of individuals. The consequence of the failure to assign duties to protect and provide is rather that any potential duties that positive law can justifiably assign to TNCs cannot go beyond the universal perfect duty to do no harm, because the source of bindingness in moral theory remains wanting. However, the means through which to achieve compliance of TNCs with human rights norms are not exhausted. TNCs can be incentivized and externally forced to better fulfil their imperfect duties. These duties do not ground rights, as they are held by some and owed to no one in particular. An individual can therefore not raise human rights claims to TNCs. But the discretionary character of imperfect duties does not imply that there are no mechanisms of limiting their indeterminacy and even enforcing them. Soft-law instruments such as the UNGPs are best interpreted as concretizations of imperfect duties rather than human rights mechanisms because of their insufficient grounding in moral theory.

Imperfect duties leave discretion as to what constitutes their adequate performance, but this does not imply that they are not weighty. Moreover, there are multiple ways to make imperfect duties more determinate through both soft-law measures and new interpretations of existing legal mechanisms outside of international human rights law. Additionally, because "international human rights law is not renowned for its enforceability", a focus on imperfect duties might prove more fruitful than a blind reliance on human rights law and the required special perfect duties (Nolan 2013, 160). In the remainder of this article, one such approach, seeking to increase enforceability of human rights norms outside of human rights law and thereby limit the wiggle room for businesses in discharging their imperfect duties, will be introduced and further elaborated.

The approach this section introduces is not limited by the criterion that there can be no discretion as to what constitutes an adequate performance of the duty. Thus, focusing on the imperfect duties of TNCs does not create a causal relationship between infringements of human rights and accountability for violations of human rights. This is because an imperfect duty does not have counterpart rights, due to it being owed to no one. Bearing in mind that much of the wiggle room businesses have is due to our statist constellation of international law and the general reluctance of states to regulate TNCs through international treaty law, the criterion that the state's role in regulating TNCs must be minimal is maintained. ${ }^{29}$

\footnotetext{
$\overline{{ }^{29}}$ This does not imply that states cannot do more or do not have (moral) duties to regulate.
} 


\section{Indirect Legal Mechanisms}

Recent years have witnessed a growing literature on and practice of limiting the discretion of TNCs. Proposals made within this body of literature can be interpreted as not seeking to hold TNCs directly accountable for human rights, in line with TNCs' duties being imperfect but rather being aimed at indirectly achieving the end of limiting TNCs' infringements of the human rights of individuals. Examples include NGO pressure, consumer awareness and the development of soft-law norms such as the UNGPs. To a great extent, such examples focus on the private relationships between TNCs and consumers, thereby largely excluding states. ${ }^{30}$

One approach is taken to exemplify the larger range of methods that focus on limiting the discretion of TNCs (regarding the extent to which their conduct affects human rights) through private relationships. The approach brings together two empirical facts. The first concerns individuals acting (predominantly) as consumers in our globalized world. Individuals increasingly behave "ethically" by making deliberate purchasing decisions regarding the circumstances under which products are produced. Secondly, TNCs have established extensive corporate codes of conduct and corporate social responsibility that relate, inter alia, to their human rights responsibilities. Just as the approach under review here, these approaches intend to take TNCs' codes of conduct seriously and search for ways to legally enforce their content, especially their commitment to human rights without seeking direct recourse to human rights and their demanding moral justification.

In Conformity of Goods, the Network Society, and the Ethical Consumer, Hugh Collins (2014) takes a legal approach to the issue of TNCs and human rights. He proposes a novel interpretation of existing legal instruments, according to which consumers can hold TNCs accountable for violating their codes of conduct, which often include human rights standards, international labour standards, local labour law and other accepted standards relating to the chain of production. Collins' argument will be introduced before being assessed as a method of limiting the discretion of special imperfect duties. It will be argued that due to the conclusions of the previous section that TNCs do not bear positive human rights duties, legal instruments other than human rights law prove more fruitful in achieving the goal of TNCs' better performance in discharging their imperfect moral duties.

Collins' starting point is an exploration of the question whether contract law should be concerned "not only with the protection of weaker parties to a contract but also others who might be adversely affected by contract concluded in Europe" (2014, 621). In other words, the challenge is to integrate the effects of consumer contracts on those not party to the contract or its jurisdiction. His approach can be seen as an attempt to reinterpret traditional contract law so as to incorporate concerns for fundamental and human rights of individuals not party to the contract. The approach holds TNCs accountable for violating their self-imposed codes of conduct and thereby indirectly for violating the standards included in those codes. It can prove to be a regulatory strategy of holding TNCs indirectly accountable for violations of their universal perfect duty to avoid harming. This is particularly so, given that states are reluctant to regulate

\footnotetext{
${ }^{30}$ Even though the UNGPs leave states firmly in their role as sole addressees of international human rights law, their enforcement is located in the 'social expectations' of a greater public.
} 
and to further specify what the special imperfect duties of TNCs require. ${ }^{31}$ The carefully executed and crucial steps of Collins' argument are dealt with here only briefly.

Central to the approach are the idea of a "central hub" coordinating production of consumer goods transnationally and the notion of reasonable expectations in contract law. Firstly, Collins addresses the problem that infringements of human rights and other international standards often take place away from the act of purchasing a good. Obviously, labourers whose rights are infringed upon are not part of the consumer contract. However, production processes take place within international networks of labour in which there is a central "hub" acting as principal agent. ${ }^{32}$ Collins goes on to argue that in our increasingly networked society, simple supply chains no longer exist. Rather, they are spread out over a transnational network in which "every detail of the product, its production process, and its marketing is organized and managed by the central hub" (Collins 2014, 624). Holding TNCs accountable for acts committed outside of the central hub's jurisdiction is complex because of the strict separation of rules concerning international trade and labour standards. Collins therefore focuses on contract law generally and consumer sales law more specifically because they are governed by a single jurisdiction and are private in nature.

Secondly, Collins justifies his focus on the private relationships between consumers and TNCs by reference to the power that consumers have. Consumers, individually or as an organized collective, can boycott certain goods or organizations under their freedom of expression. States, on the other hand, are prohibited from enacting similar measures (Collins 2014, 628). In his approach, Collins extends the logic of a boycott to an interpretation of the contract law remedies available to consumers when a good does not meet their reasonable expectations. The issue is, in Collins $(2014,629)$ words:

"suppose the consumer acquires a mobile phone, but discovers shortly afterwards that it had almost certainly been manufactured using child labour, indentured labour, or working conditions that violated international labour standards, human rights, and local labour laws? Is there any remedy for the consumer who now feels that her ethical principles have been compromised?"

Collins seeks this remedy in the "reasonable expectations" of consumers with regard to the quality of a purchased good. If the expectations that a consumer can reasonably have are not met, the contract between buyer and seller can be voided. With regard to production processes and reasonable expectations, two steps are necessary to void a contract. First, it must be established that a consumer can reasonably expect that a product be produced with respect for labour standards and human rights. Second, it must be shown that this aspect is of intrinsic value to the product and thereby falls under the reasonable expectation clause.

\footnotetext{
${ }^{31}$ It must be noted that Collins does not present his view as one of increasing the determinacy of imperfect duties.

${ }^{32}$ Central hub is taken, in this paper, to refer to the central authoritative part of a transnational corporation, most likely its headquarters. For instance, Apple as a transnational corporation covers more than the headquarters in California but extends to other company locations and even their contracted production facilities. However, their central hub is located in California and is the entity that has the largest amount of control over the whole transnational corporation.
} 
The first step is to interpret TNCs' codes of conduct as expectations of process. An increasing amount of TNCs have established codes of conduct in which they outline their efforts to align the production of their goods with international standards and human rights norms. TNCs furthermore include the production process of contract parties in these codes of conduct, affirming the idea of a central hub with oversight over the larger production network. The second step is to affirm that the mode of production directly relates to the performance of a product. If it can be shown that the mode of production directly relates to performance, the consumer can reasonably expect that if a product is said to be produced in an ethical manner, this is actually the case, "even though they relate to the process by which it was produced rather than the performance of the product itself" (Collins 2014, 634). Over the last decade, TNCs have increasingly marketed and differentiated their products by referring to their "sustainable" production in relation to a wide range of international standards. Consumers, on the other hand, spend more resources than ever on products that are more expensive due to them having been produced under ethical circumstances, while possessing the same functionalities as similar products. Both TNCs and consumers alike appear to acknowledge that the circumstances of production increasingly contribute to "performance". Performance can be said to concern not only the technicalities of the product but also its history, i.e. the circumstances under which it was produced, offering new ways of making conscious market choices.

Central hubs spend significant time and resources on claiming that their products are produced in ethically justifiable ways and in accordance with international standards such as human rights. This happens through a multitude of ways, the most prominent of which are the increasing use of codes of conduct, investor agreements and stakeholder (as opposed to shareholder) influence. If, after purchasing a good, a consumer who is aware of the raised expectations finds out that despite the producer's statements the good does not possess this quality, she could argue "that her expectation of conformity in this respect has been dashed" (Collins 2014, 638). The normal remedies for breaches of expectations of conformity should thus be available "including rejection of the goods or compensation for the reduction in value" (Collins 2014, 638).

Before continuing, an intuitive unease with Collins' approach must be addressed. The issue concerning production processes that infringe upon the ability of individuals to enjoy their human rights intuitively is not that a consumer's reasonable expectations are violated but that the human rights of workers remain unfulfilled. However, as concluded in the previous sections, TNCs have no special perfect duties, so direct accountability and enforcement mechanisms will lack the necessary source of bindingness. Moreover, the imperfect duties of TNCs are indeterminate. The wiggle room can be limited only through enforceable external mechanisms, rather than through international human rights law and soft law norms. The approach, when interpreted as making imperfect duties more determinate, is not concerned with accountability for human rights violations. ${ }^{33}$

\section{Private Enforcement and Imperfect Duties}

The framework that Collins builds offers an opportunity to limit the discretion of TNCs in performing their imperfect duties justifiably through legal mechanisms other than

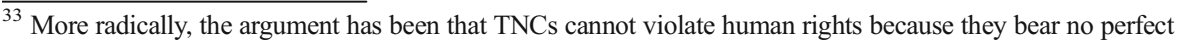
duties.
} 
human rights law. The limitation is justifiable because TNCs are not being held accountable for violations of human rights duties that cannot be assigned to them, but rather for violating expectations constituted in their private relationships with consumers. Moreover, Collins' approach offers an opportunity to indirectly hold TNCs accountable for violations of their universal perfect duty to avoid harming outside of statist international human rights law. The approach will be critically assessed as one decreasing the indeterminacy of imperfect special duties.

For two reasons, issues concerning the practical application of Collins' approach will be left aside: firstly, because the main concern is to assess the approach critically with regard to TNCs' imperfect human rights duties and, secondly, because it is beyond my expertise to predict whether courts would favourably apply Collins' approach. Therefore, it is favourably assumed that Collins' suggestions can be practically implemented through judicial or out-of-court proceedings as it arguably takes a single ruling to establish precedent. Moreover, it is assumed that such proceedings will gain the media attention needed to pressure TNCs into compliance. The concern here is to show in what ways and to which extent the approach can legitimately employ legal instruments other than human rights law in order to limit the indeterminacy of imperfect special duties and achieve the end of TNCs' compliance with their moral duties, both perfect and imperfect.

Due to the fact that Collins' approach does not include public bodies in prescribing regulation and because it is taken to exemplify a broader range of proposals, it will be hereafter referred to as the "private enforcement approach". The private enforcement approach leaves TNCs firmly in their role as private actors as it intends to indirectly hold TNCs accountable through existing private law measures. As opposed to the capacity and publicness approaches, TNCs are not reconstructed as relevantly public or capable of bearing special perfect duties. However, the extent to which the approach can restrict the discretion accessory to imperfect duties and hold TNCs indirectly accountable for violating their universal perfect duty is unclear. If a consumer purchases a good that is said to be produced under circumstances respecting the human rights of those involved, then the consumer can, in cases where this expectation is breached, attempt to (minimally) void the contract in judicial proceedings. Through the resulting public pressure, the wiggle room of TNCs in discharging their imperfect duty appears to be limited. In relation to minimal state involvement, the approach functions well given that the unable or unwilling state is not the agent holding TNCs accountable for violating their codes of conduct. The extent to which the indeterminacy of imperfect duties is limited can, however, be disputed.

Firstly, like the publicness approach, the private enforcement approach also creates a short-term incentive for TNCs to minimize their codes of conduct. Since the approach relies on private actors (i.e. consumers) to hold TNCs accountable through assumed breaches of contract and public pressure, there is still ample room for discretion. The simplest way for TNCs to avoid such problems in the future is not to increase compliance with self-imposed standards but to downscale their commitment to international standards and human rights, or make them less determinate. In doing so, they reduce the expectations raised and are less vulnerable to legal actions by consumers.

Secondly, not only is there an incentive to downscale, but there are also great differences between different TNCs' codes of conduct. Thus, the possibilities of limiting the discretion of TNCs are arbitrary. Moreover, the approach only applies to 
those TNCs that have published extensive codes of conduct. Think, for instance, of the production and assembly of Apple's iPhone taking place at Foxconn factories in China. The production process here arguably violates several international labour agreements and infringes upon the human rights of employees. Since Apple states in its code of conduct that it respects all of these standards, it can be held liable by consumers under consumer sales law. ${ }^{34}$ However, other products that do not belong to Apple are also produced at these factories, or in different factories under similar circumstances. The TNCs controlling the production of these other products might not have a code of conduct or only have a very minimal one. Consequently, this creates great differences between which actions special imperfect duties require for different TNCs.

However, such inequality in accountability is not a concern since the private enforcement approach seeks to establish accountability for the duties that TNCs assign to themselves through codes of conduct. ${ }^{35}$ Such inequality is perfectly legal within private law and is common practice: In any contract between private parties, those parties themselves determine the rights and duties specified in the contract. However, it is problematic with regard to effectively limiting the discretion that TNCs have as it potentially creates a double negative incentive. The first incentive is to downscale existing codes of conduct, and the second, for TNCs lacking codes of conduct, is to not adopt one. This discretion ultimately does not change the current practice and still leaves the fulfilment of human rights to either unwilling states or the goodwill of TNCs.

While the private enforcement approach might be a good first step forward in limiting discretion and concretizing human rights norms, such as devised in the UNGPs, for TNCs, it is likely to create counterproductive incentives. In order to circumvent these incentives, TNCs should have equal minimum human rights standards specifying their imperfect duties included in their codes of conduct. To achieve this aim, TNCs must be externally forced to incorporate these standards into a mandatory code of conduct. The state, or another political authority, such as the European Union (EU), would be the relevant actor to force TNCs to do so. Thus, while the private enforcement to a great extent works upon the basis of initiatives of private actors, a state or institution like the EU should force the inclusion of minimal standards to limit discretion. In practice, this would mean that any TNC whose central hub is located within the jurisdiction of the EU could be held liable by consumers through EU consumer sales law. The involvement of the state or state-like institutions is moreover limited and does not include enforcing human rights standards or actively holding TNCs accountable for duties that cannot be assigned to them, for both of which states have shown reluctance to do. Furthermore, individuals can play a double role: firstly, as consumers holding TNCs accountable for violations of their codes of conduct and, secondly, as citizens voting or petitioning the necessary laws limiting discretionary practices on the political agenda.

Thus, in order to limit the discretion that TNCs have in performing imperfect duties, a minimal human rights-based threshold should be included in their codes of conduct

\footnotetext{
${ }^{34}$ Apple's supplier code of conduct includes 'standards in the areas of Labor and Human Rights (...)' that apply to their suppliers' conduct. See the Supplier Code of Conduct: https://www.apple.com/supplierresponsibility/pdf/Apple_Supplier_Code_of_Conduct.pdf (visited on 7-6-2014).

${ }^{35}$ Collins might be interpreted as an example of such an approach. For both a good summary of such proposals and one of the most elaborate individual statements of this type, see Anna Beckers (2014, 317-343).
} 
by public authorities. That way, the private enforcement approach can prove to be a better method of achieving the end result of TNCs no longer infringing upon the ability of individuals to enjoy their human rights than human rights law or human rights-based softlaw. Perhaps counter-intuitively, this implies that because TNCs do not bear special perfect duties, legal instruments other than human rights instruments are best equipped to achieve the envisaged end of more virtuous TNC practices that respect the rights of all.

\section{Conclusion}

The aims of this paper were twofold. Firstly, it aimed to bridge the distance between the human rights debates in practical philosophy and in the academic literature on business and human rights. Secondly, it strove to determine to what extent TNCs can be assigned duties corresponding to rights, i.e. perfect duties, and whether recent proposals regulating the conduct of TNCs towards compliance with human rights duties are justifiable within moral theory. Given the general acknowledgement that human rights are rights that we have by virtue of our humanity, these rights, and their counterpart duties, must be sufficiently grounded within moral theory. After laying out the conception of human rights followed in this paper, it was argued that the duties corresponding to human rights must be perfect duties. Perfect duties are those duties falling on agents who have discretion as to what constitutes adequate performance of the duty, or to whom the duty is owed. They can provide the necessary basis for translation of human rights norms into binding positive law.

Corresponding to human rights, three duties are identified in the literature: duties to respect, protect and provide. For these duties to be legally enforced through positive human rights law, they must be grounded in either universal perfect duties, i.e. the negative duty to avoid harming, or in special perfect duties, i.e. those duties that require action, rather than omission, to establish the content of the counterpart right. Universal perfect duties correspond to liberty rights, whereas special perfect duties have counterpart rights to good and services. With regard to the issue of TNCs and human rights, two approaches from practical philosophy that seek to assign special perfect duties to protect and provide for human rights to TNCs were assessed: the capacity approach and publicness approach. The capacity approach, it was argued, failed to assign special perfect duties to TNCs because of the inability to establish a criterion to determine what constitutes excessive costs in the discharge of these duties. The publicness approach was found to be flawed due to the discretion it left for TNCs in establishing what counts as adequate performance of the assigned human rights duties.

Concluding that TNCs do not bear special perfect duties corresponding to human rights, an argument was introduced in favour of interpreting TNCs' human rights duties as imperfect duties corresponding to virtues. Through an assessment of the private enforcement approach based on recent arguments by Hugh Collins, this paper argued that such approaches are better equipped to achieve the end of TNC compliance with human rights norms. Although imperfect duties have no counterpart rights, their content can, justifiably, be made less indeterminate through legal mechanisms that exist outside of human rights law and are potentially better equipped to regulate TNCs. The conclusion that TNCs do not bear special perfect duties, however, reinforces arguments made by others that TNCs are not relevant subjects of international human 
rights law. However, this article concludes that this point is not necessarily defeating, given that imperfect duties can be made more stringent by increasing their determinacy through instruments other than human rights law.

A number of important questions remain unanswered and require further research. First, approaches such as Collins' must be studied further within their legal context and their potential viability before courts. A number of issues relate to such forms of legal activism, not the least of which is whether courts are legitimate in playing such a political role. Second, with respect to such existing soft-law human rights norms as the UNGPs, questions arise as to their capability to create duties grounded in moral theory. If, as has been argued here, the UNGPs are best interpreted as a method of limiting the determinacy of imperfect duties, their status as human rights norms (albeit of soft-law) can be contested, as imperfect duties have no counterpart rights. Finally, this could well lead to the conclusion that, firstly, human rights law has little bearing on the regulation of the conduct of private actors, besides providing a common vocabulary. Secondly, that focus should be on limiting the discretion of imperfect duties, rather than assigning perfect duties without the necessary ground of bindingness, as a step towards positive international law.

Acknowledgments I would like to thank A.L.B. Colombi-Ciacchi, A. Zwitter, R.G.P. Peters, C.L. Lane and two anonymous reviewers for their comments and suggestions. An earlier version of this paper has been presented at the biannual conference of the ECPR Standing Group on Regulatory Governance in Barcelona, 2014.

Open Access This article is distributed under the terms of the Creative Commons Attribution 4.0 International License (http://creativecommons.org/licenses/by/4.0/), which permits unrestricted use, distribution, and reproduction in any medium, provided you give appropriate credit to the original author(s) and the source, provide a link to the Creative Commons license, and indicate if changes were made.

\section{References}

Beckers A (2014) Taking Corporate Codes Seriously. Dissertation, Maastricht University.

Cernic J L (2010) Human Rights Law and Business: Corporate Responsibility for Fundamental Human Rights. Europa Law Publishing, Groningen.

Collins H (2014) Conformity of Goods, the Network Society, and the Ethical Consumer. European Review of Private Law 22 5: 619-640.

Dann GE, Haddow N (2008) Just Doing Business or Doing Just Business: Google, Microsoft, Yahoo! and the Business of Censoring China's Internet. Journal of Business Ethics 79 3: 219-234.

Deva S (2013) Treating human rights lightly: a critique of the consensus rhetoric and the language employed by the Guiding Principles. In Deva S \& Bilchitz D (eds) Human Rights Obligations of Business; Beyond the Corporate Responsibility to Respect? Cambridge University Press, Cambridge, pp 78-104.

Deva S (2014) The Human Rights Obligations of Business: Reimagining the Treaty Business, www.businesshumanrights.org/sites/default/files/media/documents/reimagine_int_law_for_bhr.pdf (Last accessed 2309-2015).

Deva S, Bilchtiz D (2013) Human Rights Obligations of Business; Beyond the Corporate Responsibility to Respect? Cambridge University Press, Cambridge.

Douzinas C (2000) The End of Human Rights. Hart Publishers, Oxford.

Enneking LFH (2012) Multinational Corporations, Human Rights Violations and a 1789 US State - A Brief Exploration of the Case of Kiobel V. Shell. Nederlands Internationaal Privaatrecht 369 3: 396-400.

Feinberg J (1973) Social Philosophy. Prentice-Hall, New Jersey.

Goodin RE (1988) What is so Special about our Fellow Countrymen?. Ethics 98 4: 663-686.

James A (2012) Justice as Fairness; A Social Contract for our Global Economy. Oxford University Press, Oxford. 
Kant I (2008/1785) Groundwork of the Metaphysics of Morals. In: Sedgwick S (ed) Cambridge University Press, Cambridge.

Karp DJ (2014) Responsibility for Human Rights; Transnational Corporations in Imperfect States. Cambridge University Press, Cambridge.

Knox JH (2012) The Ruggie Rules: Applying Human Rights Law to Corporations. In Mares R (ed) The UN Guiding Principles on Business and Human Rights. Brill Publishers, Leiden, pp 51-83.

Meckled-Garcia S (2008) On the Very Idea of Cosmopolitan Justice: Constructivism and International Agency. The Journal of Political Philosophy 16 3: 245-271.

Meckled-Garcia S (2009) Do Transnational Economic Effects Violate Human Rights?. Ethics \& Global Politics 2 3: 259-276.

Meckled-Garcia S (2013) Is There Really a Global Human Rights Deficit? Consequentialists Liability and Cosmopolitan Alternatives. In Brock G (ed) Cosmopolitanism versus Non-Cosmopolitanism: Critiques, Defenses, Reconceptualizations, Oxford University Press, Oxford, 111-126.

Miller D (2001) Distributing Responsibilities. The Journal of Political Philosophy 9 4: 453-471.

Nolan J (2013) The Corporate Responsibility to Respect Human Rights: Soft Law or not Law?. In: Deva S, Bilchtiz D (ed) Human Rights Obligations of Business; Beyond the Corporate Responsibility to Respect?. Cambridge University Press, Cambridge, pp 138-161.

O’Neill O (1996) Towards Justice and Virtue: A Constructivist Account of Practical Reasoning. Cambridge University Press, Cambridge.

O’Neill O (2001) Agents of Justice 32 1-2 Metaphiosophy 32 1-2: 180-196.

O’Neill O (2004) Global Justice: Whose Obligations?. In: Deen L. Chatterjee DL (ed) The Ethics of Assistance Morality and the Distant Needy, Cambridge University Press, Cambridge, pp 242-259.

O’Neill O (2015) Reply to Tasioulas. In: Cruft R, Matthew Liao S, Renzo M, Philosophical Foundations of Human Rights. Oxford University Press, Oxford, pp 71-78.

Pettit P (2007) Responsibility Incorporated. Ethics 117: 171-201.

Pogge T (2002) World Poverty and Human Rights. Polity Press, Cambridge.

Rawls J (1999) The Law of Peoples. Harvard University Press, Cambridge, MA.

Raz J (2010) Human Rights in the Emerging World Order. 1, 1 Transnational Legal Theory 1 1: 31-47.

Sen A (2004) Elements of a Theory of Human Rights. Philosophy \& Public Affairs 32 4: 315-356.

Tasioulas J (2015) On The Foundations of Human Rights. Cruft R, Matthew Liao S, Renzo M, Philosophical Foundations of Human Rights. Oxford University Press, Oxford, 45-70.

Teubner G (2006) The Anonymous Matrix: Human Rights Violations by "Private" Transnational Actors. Modern Law Review 69 3: 327-346.

United Nations Human Rights Council (UNHCR), Elaboration of an international legally binding instrument on transnational corporations and other business enterprises with respect to human rights, $\mathrm{A} / \mathrm{HRC} / \mathrm{RES} /$ 26/9, 14-07-2014. http://ap.ohchr.org/documents/dpage_e.aspx?si=A/HRC/RES/26/9 (Last accessed 2209-2015).

United Nations Human Rights Council, Guiding Principles on Business and Human Rights: Implementing the United Nations "Protect, Respect and Remedy" Framework', A/HRC/17/31 (21 March 2011).

Wenar L (2007) Responsibility and Severe Poverty. In: Pogge T (ed) Freedom from Poverty as a Human Right: Who Owes What to the Very Poor, Oxford University Press, Oxford, pp 255-274.

Weschka M (2006) Human Rights and Multinational Enterprises: How Can Multinational Enterprises Be Held Responsible for Human Rights Violations Committed Abroad? Heidelberg Journal of International Law 66: 625-661. 